\title{
A gestão do conhecimento sobre os canais de autoatendimento de uma cooperativa de crédito
}

\author{
The management of knowledge about the self-service channels of a credit union
}

\begin{abstract}
Resumo
Cooperativas de crédito têm diante de si, um grande desafio no aperfeiçoamento e investimento em tecnologia, relacionando-se aos canais de autoatendimento e, quanto ao preparo das pessoas para desenvolver este conhecimento. $O$ objetivo desta pesquisa foi analisar a gestão do conhecimento dos colaboradores de uma cooperativa de crédito, sobre canais de autoatendimento oferecidos aos seus associados, verificando necessidade de melhorias ao setor de gestão de pessoas, relacionadas à capacitação dos mesmos. A metodologia de pesquisa utilizada foi exploratória e descritiva, com análise quantitativa dos dados e, com técnicas de levantamento e pesquisa bibliográfica, coletando os dados através de um questionário aplicado a funcionários de Caixa e Assistentes de Atendimento. Os resultados alcançados apresentam a importância do conhecimento, a busca pela atualização e também da disseminação aos associados quanto ao uso dos canais alternativos e, também, as dificuldades existentes e necessidades de melhorias tecnológicas quanto às ferramentas e treinamento.
\end{abstract}

Palavras-chave: Conhecimento; Cooperativa de crédito; Canais de autoatendimento; Colaboradores

\begin{abstract}
Credit co-operatives have before them a great challenge in the improvement and investment in technology, relating to the channels of self-service and, as to the preparation of the people to develop this knowledge. The objective of this research was to analyze the management of the knowledge of the employees of a credit cooperative, about self-service channels offered to their associates, verifying the need for improvements to the personnel management sector, related to their qualification. The research methodology used was exploratory and descriptive, with quantitative analysis of the data and, with survey and bibliographic research techniques, collecting the data through a questionnaire applied to Caixa employees and Attendants. The results show the importance of knowledge, the search for updating and also the dissemination to the members regarding the use of alternative channels, as well as the existing difficulties and technological improvement needs regarding tools and training.
\end{abstract}

Keywords: Knowledge; Credit cooperative; Self-service channels; Employees

Recebido: 29/09/2017 Aceito: 01/02/2018

Cristiane Weschenfelder Schneider ${ }^{1}$, Leandro Dorneles dos Santos ${ }^{2}$, Flavia Luciane Scherer ${ }^{3}$, Edio Polacinski ${ }^{4}$

${ }^{1}$ Especialização em Contabilidade Avançada. Universidade Regional Integrada do Alto Uruguai e das Missões - URI criswwss@gmail.com

${ }^{2}$ Doutorando em Administração na Universidade Federal de Santa Maria - UFSM. - leandro1902@ gmail.com

${ }^{3}$ Mestre em Gestão Estratégica de Organizações, pela Universidade Regional Integrada do Alto Uruguai e Missões - URI, Campus de Santo Ângelo/RS - flaviascherer@globo.com

${ }^{4}$ Graduada em Administração pela UFSM, mestre em Administração pela UFSC e dr. ${ }^{a}$ em Administração pela UFMG.

Mestre - UFSM e Especialista - URCAMP em Engenharia de Produção. - edio.pk@gmail.com 


\section{Introdução}

conhecimento continua sendo, cada vez mais,

$\mathrm{O}$ de fundamental importância no meio profissional e na sociedade como um todo, destacando-se que o Banco Mundial entende que o conhecimento se tornou indispensável para o sucesso econômico, dos países e organizações e, a gestão do conhecimento nas organizações se tornou crítica para sustentar esse sucesso em longo prazo (SRIKANTAIAH; KOENIG, 2008).

Neste sentido, o conhecimento apresenta-se como um dos assuntos que expressam necessidades constantes de acompanhamento e aprimoramento por parte das organizações, pois a gestão do conhecimento apresenta-se com um desafio constante num ambiente altamente competitivo de reaprender a aprender, mantendo-se alinhadas com as estratégias organizacionais (TEIXEIRA; PIZOLOTTO; LAMPERT, 2004)

O conceito de gerenciamento do conhecimento segundo Richter (2002) apud Teixeira, Pizolotto e Lampert (2004, p. 3897)

foi tema de inúmeras discussões por gerentes e executivos e também por responsáveis pela implantação da Gestão do Conhecimento em empresas europeias e, resultaram nos processos que governam a criação, disseminação e utilização do conhecimento para atingir plenamente os objetivos da organização, ou seja, trata-se fundamentalmente de uma forma de alavancar a eficácia organizacional, que se utiliza de elementos presentes no comportamento individual/grupal, nas tecnologias de informação e nos elementos estruturais da organização.

O objeto de análise deste trabalho foi uma cooperativa de crédito, que segundo dados estatísticos do Banco Central, faz parte de um grupo de organizações cooperativas que representam o $6^{\circ}$ maior banco do país, com 7,8 milhões de pessoas e empresas associadas, mas são apenas 3\% do sistema financeiro, tendo como principal desafio, ganhar maior escala (ÉPOCA NEGÓCIOS, 2016). Assim, sem dúvida, a gestão do conhecimento pode auxiliar a enfrentar este desafio e, segundo Carvalho (2011), o uso dos serviços e meios oferecidos aos cooperados é muito importante, já que estes são sócios, donos e também usuários do sistema.

Por este motivo, a presente investigação buscou resolver a seguinte questão: como o conhecimento a respeito dos canais de autoatendimento de uma cooperativa de crédito é desenvolvido e disseminado entre os colaboradores e os clientes que utilizam estes canais?

Para tanto, o objetivo desta pesquisa foi analisar a gestão do conhecimento dos colaboradores de uma cooperativa de crédito, sobre os canais de autoatendimento oferecidos aos seus associados, a fim de verificar a necessidade de melhorias ao setor de gestão de pessoas, relacionando-se a capacitação dos mesmos.

Sendo assim, justifica-se esta investigação pela importância de avaliar a efetividade dos treinamentos utilizados pela cooperativa de crédito a respeito dos canais de autoatendimento e, consequentemente, pela importância da pesquisa para a organização, pois o uso da tecnologia está em crescente evolução devido a necessidade de otimização do tempo e custos, justificando assim, também, para os cooperados que buscam na cooperativa os serviços de acordo com a sua necessidade, sendo que estão cada vez mais evoluídos, utilizando a internet para facilitar e agilizar suas movimentações financeiras.

\section{Referencial teórico}

Neste tópico serão abordados os referenciais teóricos sobre cooperativismo, cooperativas de crédito, sua abrangência no Brasil, evolução dos canais de autoatendimento no setor bancário e, a importância da capacitação de colaboradores nas organizações.

\subsection{Cooperativismo}

O cooperativismo ainda hoje se apresenta como uma forma alternativa de enfrentar a forte turbulência econômica enfrentada pelos países, conforme afirma Palhares (2004) apud Wilhelm e Schneider (2013, p. 236) quando explica que "o cooperativismo é um sistema econômico, financeiro e social e por isso precisa ser o mais eficiente, democrático e justo possível", sendo que o cooperativismo necessita, ainda, "ter clara consciência dos seus diferenciais no mercado e sociedade" (WILHELM; SCHNEIDER, 2013, p. 236).

Nos diversos conceitos sobre cooperativismo, este é enaltecido como um sistema que se opõe à política capitalista monopolista das 
grandes corporações, sendo visto por muitos como a forma ideal de gestão das interações humanas.

Para a Organização das Cooperativas Brasileiras (OCB), o cooperativismo é baseado em valores de "ajuda mútua, responsabilidade, igualdade, equidade e solidariedade", sendo que, para colocar em prática estes valores, foram estabelecidos sete princípios do cooperativismo OCB (2016, p. 7), descritos no Quadro 1.

\section{Quadro 1 - Princípios do cooperativismo}

\begin{tabular}{|c|c|}
\hline PRINCÍPIO & CARACTERÍSTICAS \\
\hline $\begin{array}{l}\text { Adesão voluntária } \\
\text { e livre }\end{array}$ & $\begin{array}{c}\text { As cooperativas são organizações voluntárias, abertas a todas as pessoas } \\
\text { aptas a utilizar os seus serviços e assumir as responsabilidades como } \\
\text { membros, sem discriminação social, racial, política, religiosa ou de } \\
\text { gênero. }\end{array}$ \\
\hline $\begin{array}{c}\text { Gestão } \\
\text { democrática }\end{array}$ & $\begin{array}{l}\text { As cooperativas são organizações democráticas, controladas pelos seus } \\
\text { membros, que participam ativamente na formulação das suas políticas e } \\
\text { na tomada de decisões. Os homens e as mulheres eleitos como } \\
\text { representantes dos demais membros são responsáveis perante estes. Nas } \\
\text { cooperativas de primeiro grau, os membros têm igual direito de voto } \\
\text { (um membro, um voto). }\end{array}$ \\
\hline $\begin{array}{l}\text { Participação } \\
\text { econômica dos } \\
\text { membros }\end{array}$ & $\begin{array}{l}\text { Os membros contribuem equitativamente para o capital das suas } \\
\text { cooperativas e controlam-no democraticamente. Parte desse capital é, } \\
\text { normalmente, propriedade comum da cooperativa. Os membros } \\
\text { recebem, habitualmente, se houver, uma remuneração limitada ao capital } \\
\text { integralizado, como condição de sua adesão. }\end{array}$ \\
\hline $\begin{array}{l}\text { Autonomia e } \\
\text { independência }\end{array}$ & $\begin{array}{l}\text { As cooperativas são organizações autônomas, de ajuda mútua, } \\
\text { controladas pelos seus membros. Se firmarem acordos com outras } \\
\text { organizações, incluindo instituições públicas, ou recorrerem a capital } \\
\text { externo, devem fazê-lo em condições que assegurem o controle } \\
\text { democrático pelos seus membros e mantenham a autonomia da } \\
\text { cooperativa. }\end{array}$ \\
\hline $\begin{array}{l}\text { Educação, } \\
\text { formação e } \\
\text { informação }\end{array}$ & $\begin{array}{l}\text { As cooperativas promovem a educação e a formação de seus membros, } \\
\text { dos representantes eleitos e dos trabalhadores, de forma que estes } \\
\text { possam contribuir, eficazmente, para o desenvolvimento de suas } \\
\text { cooperativas. Informam o público em geral, particularmente os jovens e } \\
\text { os líderes de opinião, sobre a natureza e as vantagens da cooperação. }\end{array}$ \\
\hline Intercooperação & $\begin{array}{l}\text { As cooperativas servem de forma mais eficaz aos seus membros e dão } \\
\text { mais força ao movimento cooperativo, trabalhando em conjunto, através } \\
\text { das estruturas locais, regionais, nacionais e internacionais. }\end{array}$ \\
\hline $\begin{array}{l}\text { Interesse pela } \\
\text { comunidade }\end{array}$ & $\begin{array}{l}\text { As cooperativas trabalham para o desenvolvimento sustentado das suas } \\
\text { comunidades, através de políticas aprovadas pelos membros. }\end{array}$ \\
\hline
\end{tabular}

Fonte: OCB (2016, p. 8-10).

Ainda numa reflexão no terceiro milênio apresentada por Rodrigues (2004) apud Wilhelm e Schneider (2013, p. 236), este diz que "o cooperativismo, passa a ter uma função além de social e econômica, uma nova dimensão de caráter político". Diz ainda que "o cooperativismo apresenta uma nova consistência, onde há um renascimento deste movimento, fortemente impulsionado por governos de países desenvolvidos" (WILHELM; SCHNEIDER, 2013, p. 237).

A partir desta reflexão, sendo que o cooperativismo está em plena expansão a nível 
nacional e possui diversos segmentos, neste artigo foi abordado especificamente sobre as Cooperativas de Crédito, conforme segue.

\subsection{Cooperativas de crédito}

Uma cooperativa de crédito atua no ramo de prestação de serviços financeiros e, difere de um banco, já que "são sociedades de pessoas, enquanto os bancos são sociedades de capital" (FONSECA, et al., 2009, p. 5).

Para os mesmos autores, as cooperativas de crédito

são caracterizadas como instituições financeiras monetárias, ou seja, autorizadas a captar recursos junto ao público sob a forma de depósitos à vista, podendo, portanto, criar moeda escritural, bem como os bancos comerciais, os bancos múltiplos com carteira comercial e as caixas econômicas (FONSECA, et al., 2009, p. 5).

Conforme descrevem Wilhelm e Schneider (2013), a cooperativa de crédito baseia-se em princípios e valores que buscam proporcionar melhorias e crescimento para as pessoas, principalmente quanto à qualidade de vida destas.

Ainda, segundo Pinheiro (2008, p. 7), "as sociedades cooperativas são sociedades de pessoas, com forma e natureza jurídica próprias, constituídas para prestar serviços aos associados, cujo regime jurídico, atualmente, é instituído pela Lei $n^{\circ} 5.764$, de 16 de dezembro de 1971".

De acordo com Franke (1973), quanto ao conceito de cooperativa de crédito conforme seus valores e princípios, é essencial que esta promova a defesa e a melhoria da situação econômica dos cooperados, quer obtendo para eles os mais baixos custos nos bens e serviços que necessitam, quanto colocar no mercado, a preços justos, os bens e serviços que produzem

A recente publicação elaborada em parceria da OCB, Sescoop e Banco Central do Brasil (2016) ressalta igualmente o importante papel das cooperativas de crédito, quando menciona que a variedade de produtos e serviços que são oferecidos a população contribuem para melhorar a inclusão financeira das pessoas.

Para tanto é importante salientar que as Cooperativas de Crédito possuem sua organização em Sistemas, Pagnussat (2004) apud Wilhelm e Schneider (2013, p. 122), afirma que, "a partir de
1980, o cooperativismo de crédito iniciou um novo processo de crescimento, passando para a organização sistêmica, alicerçada na padronização administrativa e operacional".

Ainda, trabalham com parcerias e possuem bancos próprios, Schardong apud Wilhelm e Schneider (2013, p. 123) diz que "os bancos cooperativos eram peças indispensáveis para que estas pudessem acessar os mecanismos operacionais próprios dos bancos comerciais, sem perderem a condição societária particular de ser cooperativa". Estão cada vez mais adequadas tecnologicamente para atender as necessidades dos associados não importando a idade ou segmento. Possuem produtos diversificados e abrangência cada vez maior que será tratada no tópico a seguir.

\subsection{Abrangência no Brasil}

No Brasil, o cooperativismo de crédito teve início em 1902, mais especificamente em 28 de dezembro, sendo que a história do Cooperativismo de Crédito brasileiro tem nome e lugar, pois como a data nos diz, há mais de um século atrás, o Pe. Theodor Amstad trouxe para o Rio Grande do Sul, uma ideia inovadora, já que, juntamente com seu trabalho social e missionário, ele foi responsável pela propagação dos ideais cooperativos, primeiramente, na cidade de Nova Petrópolis (FRANKE, 1973).

$\mathrm{O}$ grande idealizador Pe. Theodor Amstad traz em suas marcantes palavras a frase que serve de lição e faz entender ainda mais a sua doutrina, traduzindo os dois valores centrais do cooperativismo, a solidariedade entre as pessoas e a responsabilidade de cada um com a comunidade:

\footnotetext{
Se uma grande pedra se atravessa no caminho e 20 pessoas querem passar, não o conseguirão se um por um a procuram remover individualmente. Mas, se as 20 pessoas se unem e fazem força ao mesmo tempo, sob a orientação de uma delas, conseguirão solidariamente afastar a pedra e abrir o caminho para todos (AMSTAD apud SESCOOP (2016, p. 16).
}

A influência do cooperativismo está fazendo com que nos últimos anos as cooperativas de crédito aumentem em números significativas as redes de atuação. Conforme dados do Banco Central do Brasil o número de unidades de atendimento passou de 4.487 em 2010 para 5.535 em 2015, um aumento de 
$23 \%$. Esse fato decorreu principalmente do aumento de postos de atendimento (antigos Postos de Atendimento Cooperativos - PACs), que saltaram de 3.170 para 4.471 (SESCOOP, 2016). Nacionalmente, as cooperativas respondem por aproximadamente $3 \%$ dos ativos totais do Sistema Financeiro, mas em algumas regiões, como Rio Grande do Sul, este percentual vai para $11,60 \%$ no volume de depósitos do Sistema Financeiro Nacional (SESCOOP, 2016).

Ainda sobre a expansão das Cooperativas de Crédito, dados da terceira edição do Relatório de Inclusão Financeira (RIF) do Banco Central de 2015 revelam que, em 2014, as cooperativas de crédito estavam presentes em $38 \%$ dos municípios de pequeno porte e em $100 \%$ dos de grande porte (RIF, 2015, p. 44).
Sobre a dispersão geográfica dos pontos de atendimento o relatório traz que a maior concentração física ocorre nas regiões Sul e Sudeste, com $53,9 \%$ e $30,7 \%$, respectivamente. Apresentando um crescimento expressivo de $62,1 \%$ nos pontos de atendimento de cooperativas da região Norte no período 2010-2014 (RIF, 2015). Apesar desse crescimento as regiões Norte e Nordeste possuem, juntas, apenas $6 \%$ do total de pontos de atendimento, demonstrando oportunidade de crescimento do segmento nessas regiões do país. Na Tabela 1 são demonstrados os dados referentes ao crescimento do número de cooperativas comparando o ano de 2010 e 2014.

Tabela 1 - Pontos de atendimento de Cooperativas de Crédito por região

\begin{tabular}{c|c|c|c|c|c|c|c|c|c}
\hline \multirow{2}{*}{ Região } & \multicolumn{2}{|c|}{ Sede e Filial } & \multicolumn{2}{c|}{$\begin{array}{c}\text { Posto de } \\
\text { Atendimento }\end{array}$} & \multicolumn{2}{c|}{$\begin{array}{c}\text { Posto de } \\
\text { Atendimento } \\
\text { Eletrônico }\end{array}$} & \multicolumn{2}{c}{ Correspondente } & \multirow{2}{*}{ Total } \\
\cline { 2 - 11 } & 2010 & 2014 & 2010 & 2014 & 2010 & 2014 & 2010 & 2014 & \\
\hline $\begin{array}{c}\text { Centro- } \\
\text { oeste }\end{array}$ & 120 & 92 & 274 & 362 & 8 & 17 & 272 & 395 & 1.540 \\
\hline Nordeste & 143 & 98 & 153 & 193 & 3 & 4 & 4 & 17 & 615 \\
\hline Norte & 79 & 60 & 62 & 125 & 1 & 2 & 6 & 53 & 388 \\
\hline Sudeste & 626 & 538 & 1.125 & 1.364 & 355 & 730 & 157 & 260 & 5.155 \\
\hline Sul & 395 & 358 & 1.755 & 2.192 & - & - & 1.675 & 2.511 & 8.886 \\
\hline TOTAL & 3.373 & 3.160 & 5.379 & 6.250 & 2.377 & 2.767 & 4.124 & 5.250 & 32.680 \\
\hline & \multicolumn{7}{c|c}{ Fonte: adaptado de RIF (2015). }
\end{tabular}

Assim, percebe-se que as Cooperativas de Crédito estão ganhando força, bem como, possuem grandes desafios em expansão e também em atender os associados de diferentes segmentos com negócios e produtos que atendam as mais diversas necessidades, sendo que, um dos focos estratégicos que vem acompanhando a evolução da era virtual são os canais de autoatendimento - internet e mobile banking que serão abordados na sequência.
2.4 Evolução dos canais de autoatendimento internet e mobile banking

Principalmente em épocas de retração que consigam reduzir custos e ter uma vantagem diferenciada se torna necessário investir em tecnologias que possibilitem as pessoas há customizar o tempo disponível.

O Internet banking tem evoluído rapidamente nos últimos anos, sendo hoje uma das aplicações de maior sucesso, que exigem um desenvolvimento 
contínuo e altos investimentos. Conforme pesquisa realizada por Diniz (2004), a primeira onda do internet banking aconteceu entre 1996 e 1999, a partir de websites disponibilizados aos clientes para acesso a suas contas.

As pesquisas recentes comprovam um grande aumento no uso da tecnologia para o autoatendimento. Segundo pesquisa realizada pela Federação Brasileira de Bancos (FEBRABAN) em 2015, destaca-se que "as transações bancárias por celulares e tablets que tiveram crescimento de $138 \%$ em 2015, ao chegar a 11,2 bilhões de operações, ante as 4,7 bilhões em 2014, de acordo com dados divulgados hoje (31) pela Federação Brasileira de Bancos" (FEBRABAN, 2015, p. 13).

Para alcançar novos mercados e pessoas, o sistema cooperativista brasileiro tem investido em diferentes canais e tecnologias escaláveis, como correspondentes ou acesso via mobile e internet banking. E o investimento em tecnologia não perde para a rede bancária tradicional.

Conforme dados do Relatório de Inclusão Financeira (RIF, 2015, p. 58) do Banco Central do Brasil (BCB) "quanto mais a população estiver avançada na educação, ou no grau de escolaridade, tanto maior é o uso da tecnologia, fator que pode influenciar o tamanho e, principalmente, a configuração da estrutura de atendimento. A educação pode ajudar a população a conhecer e a decifrar os serviços oferecidos, reforçando a demanda, mas não necessariamente a demanda por pontos físicos de atendimento e sim pode fluir por canais eletrônicos de atendimento (internet banking e celulares), reduzindo a demanda por pontos físicos".

Ainda conforme divulgado pela FEBRABAN (2015) o internet banking possibilitou $33 \%$ das transações em 2014, enquanto que o mobile banking alcançou $21 \%$ delas. O Brasil ocupa o $7^{\circ}$ lugar em investimentos em tecnologia da informação no setor bancário. Em 2015, a soma desses investimentos totalizou $\mathrm{R} \$ 19,2$ bilhões, dos quais $44 \%$ destinados a software, $35 \%$ a hardware e $20 \%$ a telecom, mas, mesmo assim, o número foi mais baixo do que o registrado em 2014: R \$ 21 bilhões (FEBRABAN, 2015).

É evidente o crescimento do uso dos meios tecnológicos, porém, estes meios dependem da internet para pleno acesso aos serviços financeiros disponíveis. Outro fator fundamental já destacado anteriormente é a educação, o conhecimento tanto por parte dos usuários e, principalmente, por parte dos profissionais que oferecem os serviços, tema em evidência que será abordado a seguir, buscando entender de que forma a gestão do conhecimento é importante neste processo.

\subsection{Gestão do conhecimento}

É fundamental entender qual o significado da gestão do conhecimento, devido a sua relevância na atualidade. Segundo Takeuchi e Nonaka (2008, p. 7), compreende "o processo de criar continuamente novos conhecimentos, disseminando-os amplamente através da organização e incorporando-os velozmente em novos produtos/serviços, tecnologias e sistemas".

Fato é que as corporações estão cientes que o grande desafio diante da alta competitividade é entender de pessoas que são as detentoras do conhecimento, que significa de forma sintetizada contabilmente, o capital intangível, difícil de mensurar, mas que representa uma estratégia de vantagem competitiva sustentável.

A gestão do conhecimento amplia as possibilidades de aprendizagem para indivíduos e organizações, sendo um fator crítico de sucesso. Davenport (1998) apud Neto (2008, p. 18) reconhece a dificuldade de definir, por exemplo, o termo "informação" isoladamente, e reitera que as tentativas de fazê-lo por meio da distinção entre dado e conhecimento são nitidamente imprecisas, sendo que sua proposta compreensiva se consolida pela elaboração de um processo dados-informaçãoconhecimento.

Assim, a gestão do conhecimento está relacionada diretamente ao capital humano, que é responsável pela criação e retenção do conhecimento, que por sua vez é considerado como valor diferenciado nas empresas que buscam o sucesso perene, agregando valor de mercado. Desta forma, a seguir será abordada a importância da capacitação (ou treinamento) dos indivíduos considerados como capital humano.

\subsection{Importância da capacitação}

A capacitação tem a finalidade de promover a educação das pessoas nas corporações, pois, em plena era da informação, o conhecimento é a moeda 
mais valiosa dos negócios. Conforme Chiavenato (2009), quando se desenvolve as pessoas elas desenvolverão a organização. $\mathrm{O}$ autor afirma também que o crescimento individual conduz ao crescimento das equipes, o qual conduz ao crescimento das áreas funcionais e este, ao crescimento da organização.

Assim, o treinamento é o aperfeiçoamento de desempenho, já que prepara o colaborador para as inovações tecnológicas e as constantes mudanças no mercado. $\mathrm{O}$ uso do Treinamento proporciona melhorias para os colaboradores, capacitando e valorizando-os, para que os mesmos sejam desenvolvidos dentro da empresa e, ao mesmo tempo, a empresa consiga motivação e integração entre seus colaboradores, proporcionando diferencial na qualidade do produto ou serviço no mercado em que atua. Neste contexto, segundo Morassutti e Grisci (2002) apud Teixeira, Pizolotto e Lampert (2004), no trabalho bancário, novas tecnologias são inseridas de maneira muito rápida, fazendo com que os colaboradores tenham que se adaptar de forma flexível quanto ao conhecimento e utilização prática destas novas tecnologias em sua rotina.

Segundo Aquino (1980) apud Carlos, Bazon e Oliveira (2012) o treinamento visa fornecer ao empregado, melhores conhecimentos, habilidades e atividades para que não se dissolva das inovações em relação ao seu campo de atividade e das profundas mutações do mundo que o cerca. $\mathrm{O}$ desenvolvimento tem como objetivo, explorar o potencial de aprendizagem, e a capacidade produtiva do colaborador, tendo novas habilidades $\mathrm{e}$ conhecimentos, o desenvolvimento maximiza o desempenho profissional e motivacional do colaborador.

Segundo Chiavenato (2000) apud Carlos, Bazon e Oliveira (2012), Desenvolvimento Profissional é a educação que visa ampliar, desenvolver e aperfeiçoar o homem para seu crescimento profissional em determinada carreira na empresa ou para que se torne mais eficiente e produtivo no seu cargo.

As empresas que capacitam e treinam seus funcionários, que são as peças chave, o patrimônio maior da organização, estão mais bem preparadas para os desafios e inovações e, esse patrimônio tem que estar se atualizando com todas as mudanças, sejam elas organizacionais ou tecnológicas, para que os objetivos e metas da empresa sejam obtidos com mais qualidade. Isso faz com que os seus produtos ou prestações de serviços agreguem um maior valor e, com isso, a organização tenha uma maior satisfação dos seus clientes e colaboradores.

Isso explica as diversas formas que os indivíduos possuem em aprender, reter o conhecimento, aperfeiçoar o saber. $\mathrm{O}$ grande desafio das empresas está em utilizar os meios de acordo com cada situação.

\section{Método}

O presente artigo é de natureza aplicada, pois conforme explica Gil (1999), apresenta uma característica fundamental que é o interesse na aplicação, utilização e consequências práticas do conhecimento. Ainda, as pesquisas podem ser classificadas em exploratórias, explicativas e descritivas (GIL, 2010), sendo que esta caracterizouse como exploratória, que segundo Gil $(1999$, p. 43) "visa a proporcionar uma visão geral de um determinado fato, do tipo aproximativo", quando buscou-se verificar o nível de conhecimento dos colaboradores de uma Cooperativa de Crédito quanto ao uso de canais e autoatendimento. Também, como descritiva, que para Gil (1994) tem como objetivo primordial a descrição das características de determinada população, fenômeno ou estabelecimento das relações entre variáveis, uma vez que foram descritas as características dos colaboradores que desempenham a função de Caixa e Assistentes de Atendimento.

Quanto à abordagem usada na pesquisa, destaca-se que foi a quantitativa, que considera aquilo que pode ser quantificável, o que significa traduzir em números, opiniões e informações para classificá-los e analisá-los (GIL, 2008, p. 176).

Em relação aos procedimentos, caracterizouse como levantamento, uma vez que a pesquisa se caracterizou "pela interrogação direta das pessoas, cujo comportamento se deseja conhecer" (GIL, 2010, p. 35). Também, utilizou-se a pesquisa bibliográfica, quando foram utilizados materiais já publicados para pesquisa do referencial teórico, como livros, artigos, monografias, além de materiais disponíveis na internet (GIL, 2010).

O universo da pesquisa compreendeu 128 indivíduos, contemplando os Caixas e Assistentes de Atendimento das Agências do Sicredi União - RS. Para tanto, a amostragem foi calculada a partir da 
perspectiva de Bruni (2011, p. 198), através da Equação 1:

$$
n=\frac{Z^{2} \times p(1-p) \times N}{(N-1) \times e^{2}+Z^{2} \times p(1-p)}
$$

Sendo:

$\mathrm{n}$ - amostra calculada;

$\mathrm{N}$ - população $=128$;

$\mathrm{Z}$ - desvio do valor médio que aceitamos para

alcançar o nível de confiança desejado: 1,96 ;

$\mathrm{p}$ - heterogeneidade da amostra: $80 \%$;

$\mathrm{e}$ - erro amostral: $5 \%$.

Substituindo os valores na fórmula, tem-se:

$$
\begin{gathered}
n=\frac{1,96^{2} \times 0,8(1-0,8) \times 128}{(128-1) \times 0,05^{2}+1,96^{2} \times 0,8(1-0,8)} \\
n=\frac{3,8416 \times 0,16 \times 128}{127 \times 0,0025+3,8416 \times 0,16} \\
n=\frac{78,675968}{0,3175+0,614656} \\
n=\frac{78,675968}{0,932156} \\
n=84,4021473
\end{gathered}
$$

Arredondando o valor, a amostra mínima calculada necessária para a pesquisa foi de 85 indivíduos. A pesquisa foi realizada através da aplicação de um questionário contendo 12 (doze) perguntas, onde se buscou identificar a função do colaborador, sua idade, sua percepção quanto à utilização dos canais de autoatendimento, quanto ao uso e disseminação junto aos associados, dificuldades encontradas, tempo de atualização, nível de eficiência dos treinamentos oferecidos pela Cooperativa que são à distância sobre os canais e autoatendimento e também da importância em realizar um treinamento presencial.

O questionário, instrumento de coleta, foi construído na plataforma Surveymonkey e encaminhado por e-mail aos integrantes da amostra entre os dias 14/02/2017 e 07/03/2017. Os dados coletados foram analisados a partir de tabulações na planilha eletrônica MS Excel, os quais permitiram o cruzamento de respostas e a construção de gráficos, assim como, de estatísticas descritivas, que são apresentados a seguir.

\section{Resultados e discussões}

A seguir será apresentado o resultado da pesquisa onde se buscou analisar a gestão do conhecimento dos colaboradores de uma cooperativa de crédito, sobre os canais de autoatendimento oferecidos aos seus associados, a fim de verificar a necessidade de melhorias ao setor de gestão de pessoas, relacionando-se a capacitação dos mesmos.

\subsection{Identificação da empresa alvo}

A pesquisa foi aplicada aos colaboradores do Sicredi União RS, região de abrangência local, composta por 39 municípios. A Cooperativa possui em torno de 600 colaboradores, que atuam na Superintendência e em 51 agências. Foram enviados questionários para os Caixas e Assistentes de Atendimento que desempenham um papel fundamental na disseminação do uso dos canais, sendo o universo composto por 128 colaboradores.

\subsection{Análise do perfil da amostra}

A seguir, demonstra-se a análise dos resultados onde 65 colaboradores responderam a pesquisa. Do total, 44 colaboradores são do gênero feminino e 21 são do gênero masculino. A faixa etária da amostragem ficou assim classificada: 27 colaboradores têm até 28 anos; 33 colaboradores têm entre 29 e 39 anos e 5 colaboradores estão na faixa de 40 ou mais. Os colaboradores que desempenham a função de Caixa compreenderam 44 indivíduos, enquanto que os que desempenham a função de Assistente de Atendimento, totalizaram 21 indivíduos.

\subsection{Quanto à utilização dos canais de autoatendimento}

Os respondentes foram questionados a respeito de sua rotina quanto à utilização dos canais de autoatendimento disponíveis na cooperativa e, conforme pode ser visualizada na Tabela 2, $100 \%$ 
deles utilizam o Cash; 92\% usam a Internet e, $82 \%$ utilizam o Mobile. Isso denota que existe uma parcela significativa de colaboradores (18\%) que ainda não utilizam o mobile como ferramenta de acesso a suas contas.

Tabela 2 - Utilização dos canais de autoatendimento

\begin{tabular}{c|c|c|c}
\hline Utilização & Internet & Mobile & Cash \\
\hline Não & $8 \%$ & $18 \%$ & - \\
\hline Sim & $92 \%$ & $82 \%$ & $100 \%$ \\
\hline
\end{tabular}

Fonte: dados da pesquisa (2017).

Para aqueles que não utilizam os canais listados, procurou-se o entendimento elencando alguns motivos pelo qual os colaboradores não estão utilizando esses meios e o resultado obtido é demonstrado na Tabela 3.

Tabela 3 - Utilização dos canais de autoatendimento

\begin{tabular}{c|c|c|c|c|c|c}
\hline Canal & $\begin{array}{c}\text { Não Sei } \\
\text { Utilizar }\end{array}$ & $\begin{array}{c}\text { Não Tenho } \\
\text { Internet Pessoal }\end{array}$ & $\begin{array}{c}\text { Prefiro o } \\
\text { Atendimento } \\
\text { Pessoal }\end{array}$ & $\begin{array}{c}\text { Não Tenho } \\
\text { Smartphone }\end{array}$ & $\begin{array}{c}\text { Me Sinto } \\
\text { Inseguro }\end{array}$ & $\begin{array}{c}\text { Já } \\
\text { Utilizo }\end{array}$ \\
\hline Mobile & $1,56 \%$ & $3,13 \%$ & $12,50 \%$ & $4,69 \%$ & $3,13 \%$ & $82,81 \%$ \\
\hline Cash & $1,56 \%$ & $1,56 \%$ & $1,56 \%$ & $1,56 \%$ & $1,56 \%$ & $100,00 \%$ \\
\hline Internet & $1,56 \%$ & $6,25 \%$ & $1,56 \%$ & $3,13 \%$ & $1,56 \%$ & $93,75 \%$ \\
\hline \multicolumn{7}{|c|}{ Fonte: dados da pesquisa (2017). }
\end{tabular}

Observando a Tabela 3, foi constatado como motivo principal de não acessar e realizar as transações pelo Mobile que 4,69\% dos colaboradores não possuem smartphone, que permite a instalação do aplicativo e ficou evidenciado que muitos colaboradores possuem insegurança em utilizar a tecnologia para operacionalizar, apesar de estar presente no dia-a-dia. Mesmo sendo colaboradores alguns ainda optam pelo atendimento pessoal ou não possuem internet. Quanto ao uso da internet o motivo principal de não utilizar é por não ter internet pessoal e também pela insegurança. Quanto ao uso do cash todos responderam que já usam, caracterizando-se o meio preferido pelos que responderam a pesquisa.

A Tabela 4 traz um dado muito importante para análise com relação à preferência de utilização como associados dos meios oferecidos pela Cooperativa, onde o associado é o foco principal, tanto interno (colaboradores), como externo, a quem se presta o serviço e se preza pelo bom atendimento. Para cada item foi solicitada a avaliação do $1^{\circ}$ ao $3^{\circ}$ lugar, sendo os seguintes resultados:

Tabela 4 - Preferência na utilização dos canais como associado

\begin{tabular}{c|c|c|c}
\hline Canal & $1^{\mathbf{0}}$ & $2^{\circ}$ & $3^{\circ}$ \\
\hline Internet & $25 \%$ & $50 \%$ & $25 \%$ \\
\hline Mobile & $52 \%$ & $11 \%$ & $38 \%$ \\
\hline Cash & $23 \%$ & $39 \%$ & $38 \%$ \\
\hline \multicolumn{4}{c}{ Fonte: dados da pesquisa (2017). }
\end{tabular}


O canal de autoatendimento preferido pelos respondentes da amostra é o mobile, com $52 \%$ das respostas, enquanto que a segunda preferência é a internet, com $50 \%$ de escolha. A terceira preferência ficou empatada entre o móbile e o cash, com 38\% das escolhas entre as três opções para esta posição na escala de preferência.

4.4 Quanto à oferta dos canais de autoatendimento para os associados

Como a forte tendência que se apresenta nos dias de hoje, é o uso dos meios alternativos tecnológicos, que facilitam o dia-a-dia e otimizam o tempo dos envolvidos com as operações, foi questionado aos colaboradores se os canais estão sendo oferecidos aos associados. As respostas são demonstradas na Tabela 5.

Tabela 5 - Oferta dos canais de autoatendimento aos associados

\begin{tabular}{c|c|c|c|c|c}
\hline Canal & Sempre & $\begin{array}{c}\text { Quase } \\
\text { Sempre }\end{array}$ & As Vezes & Raramente & Nunca \\
\hline Mobile & $39 \%$ & $33 \%$ & $22 \%$ & $4 \%$ & $2 \%$ \\
\hline Cash & $78 \%$ & $20 \%$ & $2 \%$ & - & - \\
\hline Internet & $48 \%$ & $36 \%$ & $16 \%$ & - & - \\
\hline \multicolumn{5}{c}{ Fonte: dados da pesquisa (2017). }
\end{tabular}

Conforme destacado na revisão bibliográfica as Cooperativas estão realizando altos investimentos em tecnologia, mesmo assim conforme evidenciado na Tabela 6 , muitos associados, $65,63 \%$, na opinião dos investigados, não têm interesse em utilizar os canais. Outro fator que dificulta a oferta é a falta de tempo durante o expediente, $46,88 \%$ das respostas e, além disso, $28,13 \%$ respondeu que a falta de paciência por parte dos associados é uma das dificuldades listadas.

Tabela 6 - Principais dificuldades quanto à utilização pelos associados

\begin{tabular}{|c|c|}
\hline Opções de Resposta & Respostas \\
\hline $\begin{array}{c}\text { Falta de tempo durante o } \\
\text { expediente }\end{array}$ & $46,88 \%$ \\
\hline $\begin{array}{l}\text { Falta de paciência por parte do } \\
\text { associado }\end{array}$ & $28,13 \%$ \\
\hline $\begin{array}{l}\text { Falta de interesse por parte do } \\
\text { associado }\end{array}$ & $65,63 \%$ \\
\hline $\begin{array}{c}\text { Não possuo capacitação para tal } \\
\text { tarefa }\end{array}$ & $3,13 \%$ \\
\hline Falta de apoio técnico & $1,56 \%$ \\
\hline Outra dificuldade (especifique): & $7,81 \%$ \\
\hline
\end{tabular}


As outras dificuldades especificadas são relacionadas principalmente ao Cash, segundo os 5 relatos, o sistema é muito complexo, precisa de melhorias para facilitar o acesso das pessoas de mais idade. Também que é muito burocrático e demorado, há muitas inserções do cartão, acaba uma movimentação e é necessário recomeçar toda a operação, ou seja, a demora é a principal dificuldade, pois as pessoas com mais dificuldade acabam desistindo de efetuar suas operações. Lentidão do sistema que deixa os associados impacientes fazendo com que desistam de prosseguir e outra colocação quanto aos associados aposentados, os quais possuem grandes dificuldades em acessar nossos canais, muitos justificam pela idade e outros relatam não possuir conhecimento suficiente para mexer nas máquinas.

\subsection{Quanto às capacitações}

Sabendo-se que a capacitação deve ser contínua, necessária e é fundamental para o entendimento das mudanças que ocorrem de forma rápida, além de demonstrar o interesse das pessoas em aperfeiçoar o conhecimento, foi buscado através da pesquisa a respeito do tempo de atualização sobre os canais. Há quanto tempo que o colaborador buscou se atualizar e realizar uma capacitação quanto ao Mobile, Cash e Internet, tendo as seguintes respostas conforme o Gráfico 1 abaixo:
Gráfico 1 - Tempo de realização de capacitação

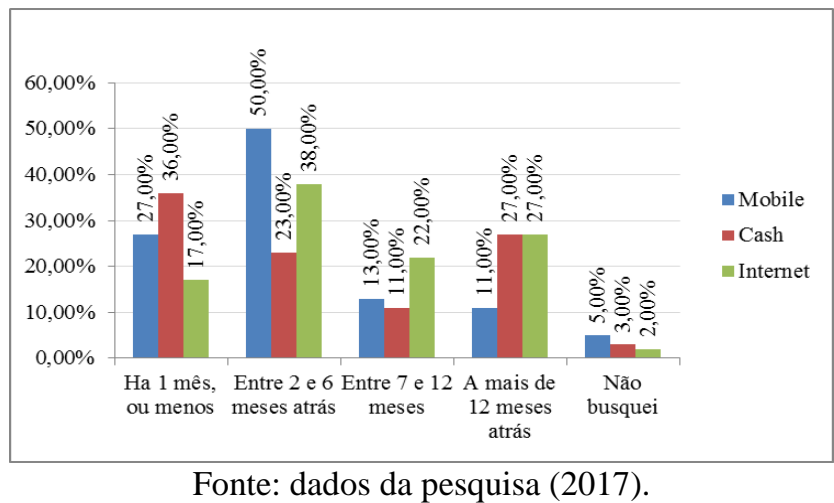

Com base na descrição acima, os colaboradores buscaram se atualizar, a maior parte das respostas foi que até 12 meses realizaram treinamentos. No período até um mês a maioria realizou treinamento quanto ao Cash, pois está sendo implantado um sistema atualizado que requer atenção para operacionalizar; entre 2 e 6 meses atrás, quanto ao Mobile; no período após os 12 meses as respostas se equivaleram quanto a busca no estudo quanto ao Cash e Internet, fato justificado por serem sistemas utilizados a mais tempo do que o Mobile. Poucos colaboradores não realizaram capacitações, em sua maior parte sobre o Mobile.

$\mathrm{Na}$ sequência e entendimento com relação aos meios de EAD oferecidos pela Cooperativa, material disponibilizado e outros itens listados abaixo, quanto a eficiência dos mesmos, seguem:

Tabela 7 - Nível de eficiência dos meios de EAD oferecidos pela Cooperativa

\begin{tabular}{c|c|c|c|c|c}
\hline Aspecto & $\begin{array}{c}\text { Muito } \\
\text { Eficiente }\end{array}$ & Eficiente & Indiferente & $\begin{array}{c}\text { Pouco } \\
\text { Eficiente }\end{array}$ & Ineficiente \\
\hline Metodologia & $34,38 \%$ & $53,13 \%$ & $7,81 \%$ & $4,69 \%$ & - \\
\hline $\begin{array}{c}\text { Material } \\
\text { disponibilizado }\end{array}$ & $35,94 \%$ & $54,69 \%$ & $7,81 \%$ & $1,56 \%$ & - \\
\hline Local & $39,06 \%$ & $39,06 \%$ & $12,50 \%$ & $6,25 \%$ & $3,13 \%$ \\
\hline $\begin{array}{c}\text { Tempo } \\
\text { disponibilizado }\end{array}$ & $35,94 \%$ & $42,19 \%$ & $4,69 \%$ & $14,06 \%$ & $3,13 \%$ \\
\hline Práticas & $34,38 \%$ & $48,44 \%$ & $10,94 \%$ & $6,25 \%$ & - \\
\hline \multicolumn{7}{c}{ Fonte: dados da pesquisa (2017). }
\end{tabular}


Como a Cooperativa utiliza a EAD como principal ferramenta para os treinamentos abordando os canais de autoatendimento, nesta pesquisa foi solicitada a opinião dos colaboradores da importância em ter um treinamento presencial. Ficou evidenciado que $82,81 \%$ dos colaboradores são a favor do treinamento, $7,81 \%$ foram indiferentes e 9,38\% acham desnecessário, conforme demonstrado na Tabela 8 .

Tabela 8 - Importância de um treinamento presencial

\begin{tabular}{c|c}
\hline Opções de Resposta & $\%$ \\
\hline Muito importante & $43,75 \%$ \\
\hline Importante & $39,06 \%$ \\
\hline Indiferente & $7,81 \%$ \\
\hline Pouco importante & - \\
\hline Desnecessário & $9,38 \%$ \\
\hline
\end{tabular}

Fonte: dados da pesquisa (2017).

Conforme o retorno acima o treinamento presencial se mostrou um ponto importante para avaliação pela Área de Gestão de Pessoas. Os meios EAD trazem os aspectos mais tecnológicos, generalistas, o que ocorre nos treinamentos presenciais é a troca de experiências com casos práticos, que muitas vezes não estão explicados nos manuais.

\section{Declaração de Direito Autoral}

Declaramos que o presente artigo é original e não foi submetido à publicação em qualquer outro periódico nacional ou internacional, quer seja em parte ou na íntegra. Declaramos ainda, que após publicado pela Revista de Gestão e Organizações Cooperativas, ele jamais será submetido a outro periódico. Também temos ciência que a submissão dos originais à Revista de Gestão e Organizações Cooperativas implica transferência dos direitos autorais da publicação digital e impressa e, a não observância desse compromisso, submeterá o infrator a sanções e penas previstas na Lei de Proteção de Direitos Autorais (nº610, de 19/02/98).

\section{Política de privacidade}

Os nomes e endereços informados nesta revista serão usados exclusivamente para os serviços prestados por esta publicação, não sendo disponibilizados para outras finalidades ou à terceiros.

\section{Conclusões}

A partir dos dados analisados foi possível verificar através da pesquisa exploratória uma visão geral aplicada em uma Cooperativa de Crédito local, o Sicredi União - RS, e também avaliar o nível de conhecimento dos colaboradores sobre a utilização dos canais de autoatendimento disponíveis como o Mobile, Cash e Internet. A amostra foi composta por 85 colaboradores, nas funções de Caixas e Assistentes de Atendimento, os quais desempenham um papel muito importante junto aos associados, sendo os cargos mais indicados pela disseminação do conhecimento sobre como utilizar os canais alternativos. Do total retornaram 65 respostas completas, sendo que a amostra mínima não foi atingida devido a muitos colaboradores estarem em férias no período da realização da pesquisa. Não foi possível mensurar quantos colaboradores, pois a ferramenta de coleta dos dados não apresenta a função dos colaboradores, sendo necessário um levantamento manual para se chegar aos mesmos.

Foi atestado pela pesquisa quantitativa que os canais são utilizados pelos colaboradores e oferecidos aos associados, porém o que pode ser observado, é que os colaboradores não possuem o tempo adequado durante o horário de atendimento para ensinar aos associados. Outro ponto trazido na pesquisa foi que os associados possuem resistência em se adaptar a esses meios, isto pode ser justificado nas respostas descritivas com relação à tecnologia utilizada e complexidade do sistema. Também ficou evidenciada a falta de paciência dos associados ou dificuldades por parte dos associados mais idosos. Foi constatado a partir disto que se faz necessário um trabalho diferenciado junto a este público mais resistente. Os colaboradores e associados mais jovens conforme os resultados apresentados, já estão adaptados à tecnologia disponível.

Outro dado importante a destacar, foi quanto à avaliação das ferramentas e capacitações oferecidas pela Cooperativa, as quais são utilizadas 
pelos colaboradores, como os treinamentos oferecidos a distância, conhecidos como EAD e, mesmo assim, foi indicada nas respostas a importância de um treinamento presencial.

O embasamento teórico foi trazido de diversos referenciais como livros, artigos, pesquisas e análises, foi fundamental no entendimento dos temas abordados, da importância das Cooperativas, seu papel junto aos associados internos e externos, a evolução dos canais alternativos, como forma de redução de custos e otimização do tempo. A valorização do capital humano, capital que não pode ser medido, mas que tem uma importância ímpar no diferencial das empresas, fazendo a diferença no atingimento dos resultados. Trouxe a gestão do conhecimento como fundamental na perenidade do sucesso e valor agregado. Do treinamento como ferramenta indispensável na retenção do conhecimento e valorização do capital humano.

O objetivo foi atingido com êxito, sendo possível através dos tipos de pesquisas realizar várias análises e contribuir com a Cooperativa, indicando as melhorias necessárias através das repostas dos entrevistados.

\section{Referências}

BRUNI, A. L. Estatística aplicada à gestão empresarial. 3. ed. São Paulo: Atlas, 2011.

CARLOS, Caroline Mazon Gomes; BAZON, Sebastião; OLIVEIRA, Wdson de. A importância do treinamento e desenvolvimento nas empresas de pequeno porte na cidade de Araras. UNAR, v. 6, n. 1, 2012. Disponível em:

$<$ http://revistaunar.com.br/cientifica/documen tos/vol6_n1_2012/2_a_importancia_do_treina mento.pdf >. Acesso em: 7 jan. 2017.

CARVALHO, Adriano Dias de. O Cooperativismo sob a ótica da Gestão Estratégica Global. São Paulo: Baraúna, 2011.

CHIAVENATO, Idalberto. Treinamento e desenvolvimento de recursos humanos: como incrementar talentos na empresa. 7. ed. Barueri, São Paulo: Manole, 2009.
DINIZ, Eduardo Henrique. Evolução e segmentação no perfil dos serviços bancários pela internet. Relatório de pesquisa $n^{\circ}$ 40. 2004. FGV Fundação Getúlio Vargas, EAESP - Escola de Administração de Empresas de São Paulo Centros de Estudos. Disponível em: $<$ http://bibliotecadigital.fgv.br/dspace/handle/ 10438/2990>. Acesso em: 11 nov. 2016.

ÉPOCA NEGÓCIOS. Cooperativas de crédito já são o $6^{\circ}$ maior banco do país. [S. 1.]: Globo, 2016. Disponível em: $<$ http://epocanegocios.globo.com/Empresa/no ticia/2016/04/cooperativas-de-credito-ja-saoo-6-maior-banco-do-pais.html>. Acesso em: 2 nov. 2016.

FEBRABAN. Relatório - Pesquisa FEBRABAN de Tecnologia Bancária 2015. Disponível em: $<$ https://cmsportal.febraban.org.br/Arquivos/d ocumentos/PDF/Relatorio Pesquisa FEBRABAN de Tecnologia Bancaria 2015.pdf>. Acesso em: 20 nov. 2016.

FONSECA, Reinaldo Aparecida; et al. A importância das cooperativas de crédito como agentes de desenvolvimento regional: um estudo na SICOOB Credicampo. Anais VI Congresso Virtual Brasileiro de Administração, 2009. Disponível em: <http://www.convibra.org/2009/artigos/198_0 .pdf>. Acesso em: 16 nov. 2016.

FRANKE, Walmor. Direito das Sociedades e Cooperativas. São Paulo. Saraiva/USP, 1973.

GIL, Antônio Carlos. Como elaborar questionários de pesquisa. 5. ed. São Paulo: Atlas. 2010.

GIL, Antonio Carlos. Métodos e técnicas de pesquisa social. - 6. ed. - São Paulo: Atlas, 2008

GIL, Antônio Carlos. Métodos e Técnicas de Pesquisa Social. São Paulo: Atlas, 1999.

NETO, Rivadávia Correa Drummond Alvarenga. Gestão do conhecimento em organizações: Proposta de Mapeamento Conceitual Integrativo - 1. ed. - São Paulo. Editora Saraiva, 2008. 
OCB Organização das Cooperativas Brasileiras. Home. 2016. Disponível em: <http://www.brasilcooperativo.coop.br>. Acesso em: 12 fev. 2017.

PINHEIRO, Marcos Antonio Henriques. Cooperativas de crédito: história da evolução normativa no Brasil.- 6. ed. - Brasília: BCB, 2008. 92 p.

RIF - Relatório de inclusão financeira. Banco Central do Brasil. - N. 3 -. Brasília: Banco Central do Brasil, 2015.

SESCOOP. Serviço Nacional de Aprendizagem do Cooperativismo. Cooperativismo de crédito: boas práticas no Brasil e no mundo. Brasília: Farol, 2016.

SRIKANTAIAH, Taverekere; KOENIG, Michael E. D. Knowledge management in practice: connections and context. Medford, New Jersey: Information Today. 2008, 519 p. Disponível em: <https://books.google.com.br/books?id=mGk ERcLc05wC\&printsec $=$ frontcover\&hl $=$ pt BR\&source $=g b s$ ge_summary_r \&cad $=0 \# \mathrm{v}=0$ nepage $\& q \& \mathrm{f}=$ false $>$ Acesso em: 14 nov. 2016.

TAKEUCHI, Hirotaka; NONAKA, Ikujiro. Gestão do conhecimento. Tradução Ana Thorell. Dados eletrônicos. - Porto Alegre: Bookman, 2008.

TEIXEIRA, Enise Barth; PIZOLOTTO, Maria Fátima; LAMPERT, Amauri Luis. A Gestão do Conhecimento em uma Organização Bancária: competências profissionais num contexto de mudanças. Anais XXIV Encontro Nac. de Eng. de Produção - Florianópolis, SC, Brasil, 3 a 5 de nov. de 2004. Disponível em: <http://www.abepro.org.br/biblioteca/enegep2 004_enegep0707_0627.pdf>. Acesso em: 11 nov. 2016.

WILHELM, Elemar José. SCHNEIDER, José Odelso. O primeiro centenário de um sonho. 1. ed. Santa Rosa: Edição do Autor, 2013. 